\title{
Pengaruh Jumlah Anggota dan Volume Usaha Pada Koperasi Simpan Pinjam di Kecamatan Buleleng
}

\author{
Emi Indarwati ${ }^{*}$, Wayang Cipta ${ }^{2}$ \\ 1,2Universitas Pendidikan Ganesha, Singaraja - Indonesia
}

\author{
A R T I C L E I N F O \\ Article history: \\ Received February, 25 \\ 2021 \\ Received in revised form \\ November, 262021 \\ Accepted November, 28 \\ 2021 \\ Available online December, \\ 252021 \\ Kata Kunci: \\ Jumlah anggota, SHU, \\ volume usaha \\ Keywords: \\ Business volume, number of \\ members, result of \\ operation.
}

\begin{abstract}
A B S T R A K
Penelitian ini bertujuan untuk menguji pengaruh jumlah anggota dan volume usaha terhadap Sisa Hasil Usaha (SHU) secara simultan maupun parsial. Desain penelitian yang digunakan kuantitatif kausal. Subjek penelitian adalah Koperasi Simpan Pinjam di Kecamatan Buleleng yang terdaftar di Dinas Perdagangan, Perindustrian dan Koperasi UKM Kabupaten Buleleng, dan objek penelitian adalah jumlah anggota, volume usaha, dan SHU. Teknik pengambilan sampel yang digunakan yaitu purposive sampling dengan jumlah sampel sebanyak 15 koperasi. Data dikumpulkan dengan pencatatan dokumen, kemudian dianalisis dengan analisis regresi linier berganda. Hasil penelitian menunjukkan bahwa (1) jumlah anggota dan volume usaha berpengaruh signifikan terhadap SHU (2) jumlah anggota berpengaruh positif dan signifikan terhadap SHU, (3) volume usaha berpengaruh positif dan signifikan terhadap SHU.
\end{abstract}

\section{A B S T R A C T}

This study aims to examine the effect of the total of members and business volume on result of operation (SHU) simultaneously or partially. The research design used quantitative causal. The research subjects are Savings and Loans Cooperatives in Buleleng District which are registered with the Buleleng Regency Trade, Industry and UKM Cooperatives Office, and the objects research are the total of members, business volume, and SHU. The sampling technique used was purposive sampling is sample many of 15 cooperation. Data were collected by documents recording, it's analyzed by multiple linear regression analysis. The results showed that (1) the total of members and business volume had a significant effect on SHU, (2) the total of members had a positive and significant effect on SHU, (3) business volume had a positive and significant effect on SHU.

\footnotetext{
* Corresponding author.

E-mail : emiindarwati18@gmail.com (Emi Indarwati)
} 


\section{Pendahuluan}

Perkembangan ekonomi Indonesia merupakan salah satu sektor yang sangat penting dan menjadi salah satu fokus pemerintah dalam membuat kebijakan untuk meningkatkan kesejahteraan masyarakat. Indonesia memiliki tiga sektor kekuatan ekonomi. Ketiga sektor tersebut adalah Badan Usaha Milik Negara (BUMN), swasta dan koperasi. Untuk dapat meningkatkan kesejahteraan masyarakat, ketiga sektor tersebut harus saling bekerjasama dan memiliki hubungan yang baik agar mencapai masyarkat yang adil dan makmur. Diantara ketiga sektor tersebut, koperasi salah satu lembaga ekonomi yang cocok dikembangkan di Indonesia karena koperasi berdiri berlandaskan asas kekeluargaan.

Koperasi adalah suatu badan usaha yang berbadan hukum dan didirikan oleh perseorangan yang anggota dan pengurusnya saling bekerja sama untuk meningkatkan nilai tambah yang dapat dimanfaatkan bagi peningkatan kesejahteraan anggotanya. Pembangunan koperasi ini diharapkan dapat menjadi wadah kegiatan ekonomi rakyat yang diarahkan agar menjadi badan usaha yang efektif dan efisien serta memberikan motivasi kepada masyarakat agar melakukan kegiatan ekonomi untuk mencapai kesejahteraan bersama. Adapun tujuan koperasi antara lain memajukan kesejahteraan anggota pada khususnya dan masyarakat pada umumnya, ikut membangun tatanan perekonomian nasional dalam rangka mewujudkan masyarakat yang maju, adil, dan makmur berlandaskan Pancasila dan UUD 1945.

Sebagai organisasi yang menjalankan suatu kegiatan usaha, selain bertujuan untuk mensejahterakan anggotanya, koperasi juga menghasilkan pendapatan atau keuntungan dari kegiatan usaha yang dilakukannya. Keuntungan yang dimiliki koperasi ini disebut dengan Sisa Hasil Usaha (SHU). Sesuai dengan Pasal 1 Ayat 12 Undang-Undang No 17 Tahun 2012 Tentang Perkoperasian dijelaskan bahwa SHU adalah Selisih hasil usaha yang diperoleh dari pendapatan koperasi dalam satu tahun buku setelah dikurangi dengan biaya-biaya. Koperasi yang memperoleh SHU yang tinggi menunjukkan bahwa koperasi tersebut memiliki kinerja yang baik sehingga dapat meningkatkan SHU yang dimiliki. Sedangkan, koperasi yang memiliki SHU yang rendah menunjukkan bahwa koperasi tersebut tidak menjalankan kegiatan operasionalnya dengan baik sehingga mengakibatkan pada penurunan SHU. Besarnya SHU pada suatu koperasi tergantung dari kegiatan yang dilakukan koperasi itu sendiri. Menurut Pachta, dkk (2005) bahwa faktor-faktor yang mempengaruhi SHU ada dua, yaitu faktor dari dalam dan faktor dari luar. Faktor dari dalam, yaitu partisipasi anggota, jumlah modal sendiri, aset, kinerja pengurus, volume usaha, kinerja manajer serta kinerja karyawan. Faktor dari luar, yaitu modal pinjaman dari luar, perilaku konsumen luar selain anggota dan pemerintah. Jumlah anggota dan volume usaha merupakan salah satu faktor yang mempengaruhi SHU koperasi. Semakin banyak jumlah anggota, maka perolehan modal koperasi akan semakin meningkat. Semakin besar modal koperasi yang terkumpul, maka semakin besar pula peluang untuk memperluas jangkauan usahanya yang nantinya akan mengakibatkan usaha koperasi akan semakin meningkat (Setiawan, 2004: 40). Dimana hal ini didukung pula oleh penelitian terdahulu yang dilakukan oleh (Raidayani, 2018) bahwa jumlah anggota dan volume usaha berpengaruh signifikan secara simultan terhadap SHU).

Subjek yang menjadi fokus dalam penelitian ini yaitu Koperasi Simpan Pinjam di Kecamatan Buleleng. Berdasarkan analisis data laporan keuangan koperasi diketahui bahwa terdapat masalah pada SHU, jumlah anggota dan volume usaha pada beberapa KSP di Kecamatan Buleleng. Adapun beberapa KSP tersebut yaitu KSP Ganesha Studi Grup dari tahun 2017 - 2019 jumlah anggota mengalami fluktuasi dan volume usaha mengalami penurunan, tetapi tidak diikuti dengan penurunan SHU melainkan mengalami peningkatan. KSP Sami Liang dari tahun 2017 - 2019 jumlah anggota tetap tidak mengalami perubahan dan volume usaha mengalami peningkatan, tetapi tidak diikuti dengan peningkatan SHU melainkan mengalami penurunan, dan KSP Eka Karya Utama dari tahun 2017 - 2019 jumlah anggota tetap tidak mengalami peningkatan maupun penurunan dan volume usaha mengalami peningkatan, tetapi tidak diikuti dengan peningkatan SHU melainkan mengalami penurunan. Dimana data laporan keuangan koperasi tersebut tidak sesuai dengan teori yang dinyatakan oleh Lukman (2005: 201) bahwa semakin tinggi jumlah anggota dan volume usaha maka tentunya akan meningkatkan SHU yang diperoleh Koperasi.

Jumlah anggota merupakan salah satu faktor penentu besar kecilnya SHU yang diperoleh koperasi. Peningkatan jumlah anggota tidak selalu menyebabkan peningkatan SHU koperasi, meningkatnya jumlah anggota dapat menyebabkan peningkatan SHU, apabila anggota tersebut memiliki peranan aktif dalam koperasi, seperti menyimpan dananya di koperasi, sehingga hal tersebut dapat menambah modal koperasi. Apaila anggota meminjam dana di koperasi tetapi melakukan pembayaran angsuran atau bunga sesuai dengan waktu yang telah ditetapkan, maka perolehan SHU akan mengalami peningkatan.

Perkembangan usaha koperasi sangat ditentukan oleh besar kecilnya modal atau dana yang dimiliki koperasi (Partomo dan Rahman, 2002: 76). Koperasi harus berusaha memperbesar volume usaha yang dimiiki dan mencari keuntungan yaitu melalui perolehan pendapatan yang maksimal untuk proses 
kegiatan usaha lebih lanjut. Dapat dikatakan bahwa semakin berkembangnya kegiatan usaha koperasi maka semakin besar modal atau dana yang digunakan untuk membiayai kegiatan usaha koperasi. Semakin berkembangnya usaha yang dilakukan koperasi maka akan memperbesar peluang koperasi dalam meningkatkan perolehan SHU.

Adapun tujuan penelitian ini yaitu untuk mengetahui: (1) pengaruh jumlah anggota dan volume usaha terhadap SHU pada Koperasi Simpan Pinjam di Kecamatan Buleleng, (2) pengaruh jumlah anggota terhadap SHU pada Koperasi Simpan Pinjam di Kecamatan Buleleng. (3) pengaruh volume usaha terhadap SHU pada Koperasi Simpan Pinjam di Kecamatan Buleleng.

\section{Metode}

Penelitian yang digunakan rancangan kuantitatif kausal, yaitu penelitian yang menggambarkan suatu generalisasi atau menjelaskan sebab akibat antara variabel yang mempengaruhi dan variabel yang dipengaruhi (Sugiyono, 2012: 37). Subjek dalam penelitian ini yaitu Koperasi Simpan Pinjam di Kecamatan Buleleng, sedangkan objek penelitian ini adalah jumlah anggota, volume usaha, dan SHU. Penelitian ini menggunakan populasi sebanyak 36 Koperasi Simpan Pinjam di Kecamatan Buleleng yang terdaftar di Dinas Perdagangan, Perindustrian dan Koperasi UKM Kabupaten Buleleng. Teknik pengambilan sampel dalam penelitian ini, yaitu menggunakan metode purposive sampling dengan kriteria: (1) KSP yang masih terdaftar aktif (2) KSP yang memiliki No. badan hukum yang tetap (3) KSP yang telah melaksanakan RAT (4) KSP yang memiliki laporan keuangan koperasi yang lengkap dan layak untuk dianalisis. Berdasarkan kriteria tersebut yang dapat dijadikan sampel dalam penelitian ini sebanyak 15 KSP yang ada di Kecamatan Buleleng.

Metode pengumpulan data yang digunakan dalam penelitian ini adalah pencatatan dokumen yaitu, dengan mengumpulkan, mencatat dan mengkaji informasi-informasi mengenai data keuangan tahunan yang berhubungan dengan masalah yang akan diteliti. Teknik yang digunakan dalam penelitian ini analisis regresi linier berganda dengan bantuan program Statistical Package For Social Sciance (SPSS) 21.0 for windows. Sebelum data diolah ke analisis regresi linear berganda, terlebih dahulu harus memenuhi persyaratan uji asumsi klasik, yaitu (1) uji normalitas, (2) uji multikolonieritas, (3) uji heteroskedastisitas, (4) uji autokorelasi.

\section{Hasil dan Pembahasan \\ a. Hasil Penelitian}

Berdasarkan dari hasil pengujian Statistical Package Social Science 21.0 for windows maka dapat diperoleh hasil pengujian berupa ringkasan hasil output SPSS analisis regresi linier berganda seperti pada Tabel 1 berikut.

Tabel 1. Ringkasan Hasil Output SPSS Analisis Regresi Linier Berganda Pengaruh Jumlah Anggota dan Volume Usaha terhadap SHU

\begin{tabular}{|c|c|c|c|c|}
\hline Parameter & Nilai & $p$-value & $\operatorname{Alpha}(\alpha)$ & Keputusan \\
\hline Ryx1X2 & 0,757 & 0,000 & 0,05 & Menolak $\mathrm{H}_{\mathrm{o}}$ \\
\hline $\mathrm{R}^{2} \mathrm{yx} 1 \mathrm{X} 2$ & 0,572 & - & - & - \\
\hline$\varepsilon$ & 0,428 & - & - & - \\
\hline Pyx 1 & 0,351 & 0,020 & 0,05 & Menolak $\mathrm{H}_{\mathrm{o}}$ \\
\hline $\mathrm{P}^{2} \mathrm{yx}_{1}$ & 0,123 & - & - & - \\
\hline Pyx2 & 0,638 & 0,000 & 0,05 & Menolak $\mathrm{H}_{\mathrm{o}}$ \\
\hline $\mathrm{P}^{2} \mathrm{yx}_{2}$ & 0,407 & - & - & - \\
\hline$\alpha$ & 19703215,040 & 0,005 & 0,05 & Signifikan \\
\hline$\beta 1$ & 39967,140 & 0,020 & 0,05 & Signifikan \\
\hline$\beta 2$ & 0,012 & 0,000 & 0,05 & Signifikan \\
\hline
\end{tabular}

Sumber: Lampiran Hasil Output SPSS

Struktur hubungan pengaruh jumlah anggota $\left(\mathrm{X}_{1}\right)$ dan volume usaha $\left(\mathrm{X}_{2}\right)$ terhadap SHU (Y) seperti tampak pada Gambar 1. 


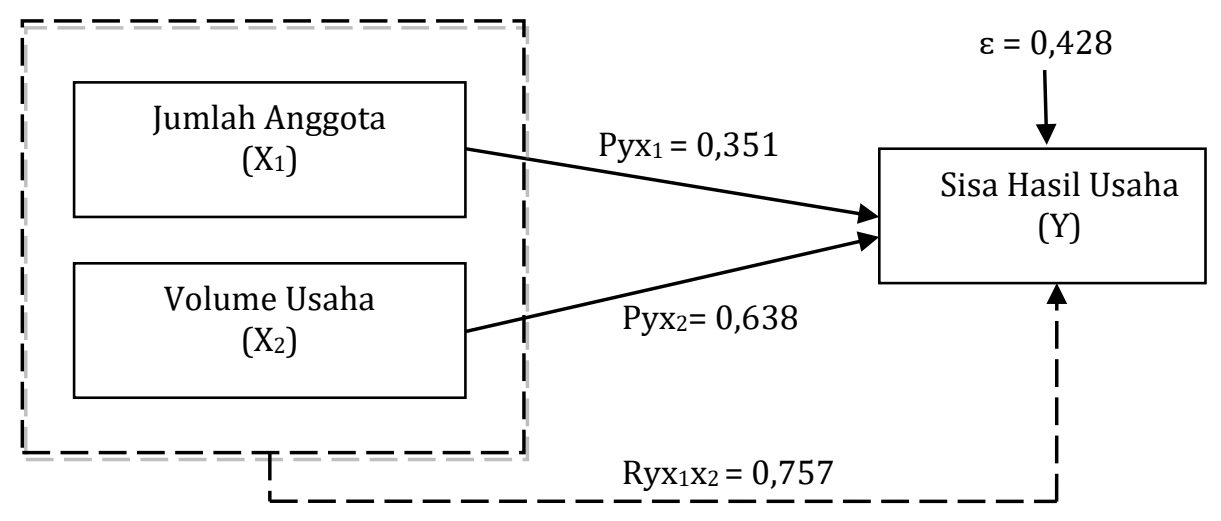

Gambar 1. Struktur Hubungan Pengaruh Jumlah Anggota $\left(X_{1}\right)$ dan Volume Usaha $\left(\mathrm{X}_{2}\right)$ terhadap SHU $(\mathrm{Y})$.

Berdasarkan hasil uji regresi berganda menunjukkan hasil Ryx $1 x_{2}=0,757$ dengan $p$-value 0,000 < alpha $(\alpha)$ 0,05 yang menyatakan bahwa $H_{o}$ ditolak yang berarti jumlah anggota dan volume usaha berpengaruh signifikan terhadap SHU pada Koperasi Simpan Pinjam di Kecamatan Buleleng. Besar sumbangan pengaruh dari jumlah anggota dan volume usaha terhadap SHU sebesar 0,572 atau 57,2\%. Sedangkan pengaruh dari variabel diluar penelitian sebesar 0,428 atau 42,8\%.

Berdasarkan hasil uji regresi linier berganda menunjukkan besarnya pengaruh jumlah anggota terhadap SHU sebesar 0,351 dengan nilai $p$-value $0,020<$ alpha $(\alpha) 0,05$ yang menyatakan bahwa $\mathrm{H}_{0}$ ditolak, berarti ada pengaruh positif dan signifikan secara parsial dari jumlah anggota terhadap SHU pada Koperasi Simpan Pinjam di Kecamatan Buleleng, dengan sumbangan pengaruh sebesar 0,123 atau 12,3\%. Pengaruh volume usaha terhadap SHU sebesar 0,638 dengan nilai $p$-value $0,000<$ alpha $(\alpha) 0,05$ yang menyatakan bahwa $\mathrm{H}_{0}$ ditolak, berarti ada pengaruh positif dan signifikan secara parsial dari volume usaha terhadap SHU pada Koperasi Simpan Pinjam di Kecamatan Buleleng, degan sumbangan pengaruh sebesar 0,407 atau 40,7\%.

Berdasarkan hasil uji regresi berganda diperoleh nilai konstanta $(\alpha)$ sebesar 19703215,040; nilai koefisien regresi jumlah anggota $\left(\beta_{1}\right)$ sebesar 39967,140 dan nilai koefisien regresi volume usaha $\left(\beta_{2}\right)$ sebesar 0,12. Sehingga persamaan regresi diformulasikan sebagai berikut.

$\mathrm{Y}=19703215,040+39967,140 \mathrm{X}_{1}+0,12 \mathrm{X}_{2}+\varepsilon$

Interpretasi hasil analisis regresi linier berganda sebagai berikut: (1) Konstanta ( $\alpha$ ) sebesar 19703215,040 artinya bahwa apabila jumlah anggota $\left(X_{1}\right)$, dan volume usaha $\left(X_{2}\right)$ nilainya sama dengan nol, maka SHU (Y) sebesar 19703215,040. (2) Nilai koefisien jumlah anggota $\left(\beta_{1}\right)$ sebesar 39967,140 berpengaruh positif terhadap SHU (Y). Hal ini mengandung arti bahwa setiap kenaikan jumlah anggota (X1) satu satuan variabel SHU (Y) mengalami kenaikan sebesar 39967,140 sehingga menjadi 19743182,18 dengan asumsi bahwa variabel bebas yang lainnya sama dengan nol. (3) Nilai Koefisien volume usaha ( $\beta_{2}$ ) sebesar 0,12 berpengaruh positif terhadap SHU (Y). Hal ini mengandung arti bahwa setiap kenaikan volume usaha $\left(\mathrm{X}_{2}\right)$ satu satuan maka variabel SHU (Y) mengalami kenaikan sebesar 0,12 sehingga menjadi 19703215,16 dengan asumsi bahwa variabel bebas yang lainnya sama dengan nol.

\section{b. Pembahasan}

Dari hasil penelitian yang telah dilakukan menunjukkan bahwa jumlah anggota dan volume usaha berpengaruh signifikan secara simultan terhadap SHU pada Koperasi Simpan Pinjam di Kecamatan Buleleng tahun 2017 - 2019. Hasil penelitian ini sesuai dengan teori Lukman (2005: 201) bahwa apabila jumlah anggota semakin banyak otomatis modal sendiri akan semakin besar sehingga semakin besar keleluasaan anggota dalam beroperasi untuk memperluas volume usahanya sehingga hal ini tentunya akan berpengaruh terhadap perolehan SHU. Maka dapat dikatakan bahwa semakin banyak jumlah anggota maka secara langsung modal koperasi akan bertambah dan dengan bertambahnya modal koperasi akan mempermudah koperasi untuk meningkatkan atau memperluas usahanya dan kemampuan koperasi untuk memperoleh SHU akan semakin meningkat. Hasil penelitian ini juga sejalan dengan hasil penelitian yang dilakukan oleh Yuliastuti dan Arie (2016) yang menemukah bahwa secara simultan terdapat pengaruh yang signifikan terhadap SHU.

Berdasarkan hasil penelitian yang telah dilakukan menunjukkan bahwa terdapat pengaruh positif yang signifikan secara parsial antara jumlah anggota terhadap SHU pada Koperasi Simpan Pinjam di Kecamatan Buleleng tahun 2017 - 2019. Hasil penelitian ini menunjukkan bahwa semakin tinggi jumlah 
anggota koperasi maka akan berdampak pada perolehan SHU. Hal ini sesuai dengan teori yang dikemukan oleh Hanel (2005) yang menyatakan bahwa pertumbuhan usaha koperasi dan peningkatan SHU pada koperasi dapat dicapai dengan peningkatan jumlah anggota. Oleh karena itu, penting bagi anggota untuk mengembangkan dan menjaga kebersamaan demi mendukung berhasilnya koperasi. Pernyataan di atas juga didukung dengan teori Baswir (2012) bahwa semakin banyak anggota koperasi yang terkumpul, maka semakin banyak masyarakat yang akan berpartisipasi dalam koperasi dan akan berpengaruh terhadap SHU. Keberhasilan suatu koperasi tidak lepas dari usaha anggota - anggotanya, maka dari itu semakin banyak jumlah anggota maka secara langsung dapat meningkatkan perolehan SHU. Hasil penelitian ini juga sejalan dengan hasil penelitian yang dilakukan oleh Raidayani, dkk (2017) yang menyatakan bahwa, jumlah anggota berpengaruh positif dan signifikan terhadap SHU.

Berdasarkan hasil penelitian yang telah dilakukan telah menunjukkan bahwa terdapat pengaruh positif yang signifikan secara parsial terhadap SHU pada Koperasi Simpan Pinjam di Kecamatan Buleleng tahun 2017 - 2019. Hasil penelitian ini menunjukkan bahwa semakin tinggi volume usaha koperasi maka akan berdampak pada perolehan SHU. Hal ini sejalan dengan teori yang dikemukakan Sitio dan Tamba (2001: 180) yang menyatakan bahwa usaha atau kegiatan yang dilakukan koperasi dapat dilihat dari besar kecilnya volume usaha yang nantinya akan berpengaruh terhadap perolehan SHU koperasi. Usaha atau kegiatan yang dijalankan oleh koperasi akan memberikan manfaat yang besar bagi anggota koperasi dan masyarakat pada umumnya. Usaha tersebut dapat dilihat dari besarnya volume usaha yang nantinya akan berpengaruh terhadap tingkat perolehan SHU koperasi. Dengan demikian dapat dikatakan bahwa semakin tinggi volume usaha maka perolehan SHU juga akan semakin tinggi. Hasil penelitian ini juga sejalan dengan hasil penelitian yang dilakukan oleh Gama dan Suryono (2018) yang menyatakan bahwa volume usaha berpengaruh positif dan signifikan terhadap SHU.

\section{Simpulan dan Saran \\ a. Simpulan}

Berdasarkan hasil penelitian yang telah dilakukan pada Koperasi Simpan Pinjam di Kecamatan Buleleng, maka dapat disimpulkan hal sebagai berikut:

1) Jumlah anggota dan volume usaha secara simultan berpengaruh signifikan terhadap SHU pada Koperasi Simpan Pinjam di Kecamatan Buleleng,

2) Jumlah anggota berpengaruh positif dan signifikan terhadap SHU pada Koperasi Simpan Pinjam di Kecamatan Buleleng,

3) Volume usaha berpengaruh positif dan signifikan terhadap SHU pada Koperasi Simpan Pinjam di Kecamatan Buleleng.

\section{b. Saran}

Berdasarkan hasil penelitian dan pembahasan serta beberapa simpulan yang telah dikemukakan, dapat diajukan saran sebagai berikut:

1) Bagi Koperasi Simpan Pinjam di Kecamatan Buleleng yang terdaftar di Dinas Perdagangan, Perindustrian dan Koperasi UKM Kabupaten Buleleng diharapkan dapat lebih mengoptimalkan jumlah anggota koperasi dan volume usaha agar dapat meningkatkan perolehan SHU. Dimana untuk meningkatkan jumlah anggota, diharapkan koperasi lebih mengembangkan usaha atau memberikan variasi simpanan atau pinjaman, agar anggota lebih tertarik untuk ikut serta dalam kegiatan koperasi. Dengan meningkatnya jumlah anggota dan memperluas volume usaha koperasi maka akan dapat meningkatkan perolehan SHU.

2) Bagi peneliti selanjutnya diharapkan agar dapat mengembangkan penelitian ini dengan menggunakan variabel penelitian lain yang mempengaruhi SHU agar penelitian yang dilakukan dapat lebih optimal dan menyeluruh. Dengan variabel yang lebih banyak dan jenis koperasi yang berbeda diharapkan penelitian selanjutnya dapat menggunakan seluruh jenis koperasi.

\section{Daftar Rujukan}

Baswir, Revrisond. 2012. Koperasi Indonesia. Yogyakarta: BPFE

Baswir. 2000. Koperasi Indonesia Edisi Pertama. Yogyakarta : BPFE.

Ferline Ariesta, dan Yolamelinda. 2014. "Pengaruh Jumlah Anggota dan Simpanan Anggota Terhadap Peningkatan Sisa Hasil Usaha (SHU) Pada PKP-RI (Pusat Koperasi Pegawai Republik Indonesia) Propinsi Sumatera Barat. Journal of Economic and Economic Education. Vol. 2, No.2, ISSN: 2302-1590.

Hanel, Alfred. 2005. Organisasi Koperasi. Yogyakarta: Graha Ilmu.

Jajang W Mahri. 2011. Pelayanan dan Manfaat Koperasi dan pengaruhnya terhadap partisipasi anggota (Studi kasus pada koperasi produsen tahu tempe pada Kabupaten Tasik Malaya). Ekonomi Koperasi. Bandung: Universitas Pendidikan Indonesia. 
Laporan RAT Tahun Buku 2017 - 2019. Buleleng: Dinas Perdagangan, Perindustrian dan Koperasi UKM Kabupaten Buleleng.

Lukman, Arifandi. 2005. Koperasi Teori dan Praktik. Jakarta: PT. Raya Grafindo Prasada

Mashitoh Gama, Bambang Suryono. 2018."Pengaruh Jumlah Anggota, Modal Luar, Modal Sendiri dan Volume Usaha Terhadap Sisa Hasil Usaha". Jurnal Ilmu dan Riset Akuntansi. Vol. 7, No.6, e-ISSN: 2460-0585.

Munir, Misbachul. 2011. "Analisis Tingkat Kesehatan Koperasi Pada Koperasi Simpan Pinjam Cendrawasih Kecamatan Gubug Tahun Buku 2011". Jurnal Ekonomi.

Nuriasih, Ni Ketut dan Ni Nyoman Yuliarmi. 2020. "Pengaruh Modal, Asset, Volume Usaha dan Jumlah Anggota Terhadap Sisa Hasil Usaha Pada Koperasi Pemasaran”. E-Jurnal Ekonomi Pembangunan Udayana. Vol. 9, No. 3, ISSN: 2303-0178.

Pachta, Andjar, dkk. 2005. Manajemen Koperasi Teori dan Praktek. Yogyakarta: Graha Ilmu.

Partomo dan Abdul Rahman. 2002. Ekonomi Skala Kecil / Menengah dan Koperasi. Jakarta: Ghalia Indonesia.

Raidayani. 2018. "Pengaruh Modal, Jumlah Anggota dan Volume Usaha Terhadap Sisa Hasil Usaha Pada Koperasi Kartika Aceh Barat Kabupaten Aceh Barat”. Jurnal Bisnis Tani. Vol. 4, No 1, ISSN: $2477-$ 3468.

Raidayani, Muhammad, Said, dan Faisal. 2017. "Faktor-Faktor yang mempengaruhi Sisa Hasil Usaha (SHU) pada Koperasi di Kabupaten Aceh Barat”. Jurnal Perspektif Ekonomi Darussalam. Vol. 3, No. 2, ISSN: 2502-6976.

Setiawan, A. Hendra. 2004. "Peningkatan Partisipasi Anggota dalam Rangka Menunjang Pengembangan Usaha Koperasi”. Jurnal Dinamika Pembangunan. Vol. 1, No.1.

Sitio Arifin, Halomoan Tamba. 2001. Koperasi Teori dan Praktik. Jakarta: Erlangga.

Sugiyono, 2012. Metode Penelitian Kuantitatif Kualitatif dan R\&D. Bandung: CV. Alfabeta.

Undang-Undang No. 17 Tahun 2012. Tentang Perkoperasian.

Winarko, Sigit Puji. 2014. "Pengaruh Modal Sendiri, Jumlah Anggota dan Aset Terhadap Sisa Hasil Usaha Pada Koperasi Di Kota Kediri. Nusantara Of Research. Vol. 1, No. 2, ISSN: 2355-7249.

Yuliastuti, Ida Ayu Nyoman dan Anak Agung Putu Gede Bagus Susadnya Arie. 2018. "Faktor-Faktor yang mempengaruhi Sisa Hasil Usaha Koperasi di Kota Denpasar". Jurnal Kependudukan Pengembangan Sumber Daya Manusia. Vol. XIV, No. 1, ISSN: 1907-3275. 